\title{
(2) OPEN ACCESS \\ Spikes in acute:chronic workload ratio (ACWR) associated with a 5-7 times greater injury rate in English Premier League football players: a comprehensive 3-year study
}

\author{
Laura Bowen $\odot_{1}^{1,2}$ Aleksander Stephan Gross, ${ }^{2}$ Mo Gimpel, ${ }^{3}$ Stewart Bruce-Low, ${ }^{3}$ \\ Francois-Xavier Li ${ }^{1}$
}

- Additional material is published online only. To view please visit the journal online (http://dx.doi.org/10.1136/ bjsports-2018-099422)

${ }^{1}$ Sport, Exercise and Rehabilitation Sciences, University of Birmingham, Birmingham, UK

${ }^{2}$ Southampton Football Club Sports Medicine and Science, Southampton, UK

${ }^{3}$ Performance Support, Southampton Football Club, Southampton, UK

Correspondence to Miss. Laura Bowen, Sport, Exercise and Rehabilitation Sciences, University of Birmingham, Birmingham B15 2TT, UK; lbowen@saintsfc.co.uk

Accepted 23 January 2019 Published Online First 21 February 2019

\begin{abstract}
Objectives We examined the relation between global positioning system (GPS)-derived workloads and injury in English Premier League football players $(n=33)$ over three seasons.

Methods Workload and injury data were collected over three consecutive seasons. Cumulative (1-weekly, 2-weekly, 3-weekly and 4-weekly) loads in addition to acute:chronic workload ratios (ACWR) (acute workload (1-week workload)) divided by chronic workload (previous 4-week average acute workload) were classified into discrete ranges by z-scores. Relative risk (RR) for each range was then calculated between injured and non-injured players using specific GPS variables: total distance, low-intensity distance, high-speed running distance, sprint distance, accelerations and decelerations. Results The greatest non-contact injury risk was when the chronic exposure to decelerations was low $(<1731)$ and the ACWR was >2.0 (RR=6.7). Non-contact injury risk was also 5-6 times higher for accelerations and low-intensity distance when the chronic workloads were categorised as low and the ACWR was $>2.0$ ( $R R=5.4-$ 6.6), compared with ACWRs below this. When all chronic workloads were included, an ACWR $>2.0$ was associated with a significant but lesser injury risk for the same metrics, plus total distance ( $R R=3.7-3.9$ ).

Conclusions We recommend that practitioners involved in planning training for performance and injury prevention monitor the ACWR, increase chronic exposure to load and avoid spikes that approach or exceed 2.0.
\end{abstract}

\section{INTRODUCTION}

Typically, top-level football players sustain two injuries per season, resulting in 50 injuries within a squad of 25 players. ${ }^{1}$ During the 2016/2017 football season, $£ 177$ million was paid out in wages to injured Premier League players, with the average wage per injury being over $£ 248000 .^{2}$ Consequently, throughout a season, clubs could be expected to pay around $£ 12.4$ million in wages alone, not including additional treatment costs, to players who are unavailable due to injury. In addition, across 24 European clubs, player availability was positively related to team success, defined by league ranking, and points per match. ${ }^{3}$

All injuries occur when an athlete is exposed to a given workload. ${ }^{4}$ Thus, each training or competition bout performed has the potential for athletic injury, indicating that inappropriate workload exposure can increase injury risk. An elevated risk of injury (relative risk $[R R]=5.1$ ) with a very high 3 -weekly accumulation of accelerations (ACC) (>9254) has been demonstrated in elite youth football players. ${ }^{5}$ More recently, a greater absolute and relative exposure in the 3 weeks prior to injury was reported in professional football players. ${ }^{6}$ In contrast, other work in elite football found that gradually increasing the exposure to moderate to high training loads produced a smaller association to injury risk than exposure to lower training loads. ${ }^{7}$ Therefore, loads should be monitored over longer periods of time, specifically, how much is performed and how they are prescribed.

Due to the increasing physical demands of the Premier League ${ }^{8}$ and the congested fixture schedule at the top level, players are required to repeatedly perform high workloads. Therefore, appropriate training loads that produce adaptations to enhance their fitness levels and tolerance to physical stress are required. ${ }^{9}$ In this case, higher workloads would appear to be protective, while lower workloads may be insufficient to induce adaptations or result in detraining thereby increasing the risk of injury. Supporting this, Gabbett's ${ }^{10}$ training-injury prevention paradox states that excessive, rapid increases in load heighten the risk of injury, whereas chronic exposure to higher loads enhances the physical capacities of the athletes making them more resilient to injury while also enhancing performance. Consequently, there has been growing support for the acute:chronic workload ratio (ACWR) as a method of prescribing appropriate training loads. This involves the assessment of the absolute 1 -week workload (acute workload) relative to 4-week chronic workload (4-week average acute workload). ${ }^{11} \mathrm{~A}$ workload index can then be calculated indicating whether the individual's acute workload is greater, less than or equal to the chronic workload they have been prepared for.

Acute workload spikes have been associated with increased injury risk in football, with metres per minute prior to injury being significantly higher than the season average. However, only 16 injuries were analysed, match data were not recorded and the ACWR was not calculated, therefore warranting further research. ${ }^{12}$ Consequently, the authors of this study investigated the relationship between the ACWR and injury risk in elite youth football 
players. A significantly increased risk of injury $(R R=2.6)$ was reported with high ACWR (1.4-1.9) for high-speed distance when the chronic workload was low $(<938 \mathrm{~m}) .{ }^{5}$ While these findings cannot be generalised, they suggest that monitoring the ACWR in professional football may be a key injury prevention strategy.

Furthermore, most studies regarding workload-injury relationships have excluded contact injuries as they are assumed to be unavoidable. However, our previous work in youth football players found very high ACWR to be associated with contact injury risk across several workload measures $(\mathrm{RR}=4.8-5.0){ }^{5}$ It was concluded that by increasing fitness levels and limiting fatigue (ie, reducing the ACWR), players may be able to respond more quickly to avoid the rapid, unpredictable movements preceding contact injury. Therefore, the inclusion of contact injuries may provide additional insight into workload-injury relationships.

Understanding the workload-injury relationship is fundamental to optimising performance and maximising player availability. Yet, there is very limited research exploring the relationships between workloads and injury in professional football. Furthermore, despite its growing popularity as a load monitoring method, the ACWR and the associated injury risks require further exploration. Therefore, we aimed to examine the relationships of accumulated workloads, the ACWR and injury risk in Premier League football across three seasons.

\section{METHOD}

\section{Participants}

Data were collected from football players $(n=33)$ from one English Premier League club (age: $25.4 \pm 3.1$ years, stature: $182.0 \pm 6.9 \mathrm{~cm}$, body mass: $79.9 \pm 7.7 \mathrm{~kg}$ ). All players trained on a full-time basis and played competitive fixtures within the Premier League during the 2014-2015, 2015-2016 and 20162017 seasons. Ten (30\%) participants competed in all three seasons, $8(24 \%)$ participants competed in two seasons and the remaining 15 competed in one season, resulting in 61 individual football seasons, analysed as independent data points. Goalkeepers were excluded from the study due to the different nature of their activity.

\section{Quantifying workload}

A global positioning system (GPS) was used to quantify workload data collected from all on-pitch training sessions and friendly matches. The GPS units (Viper 2, StatSports, Ireland), were placed between the scapulae of the players in bespoke vests. These units sampled at $10 \mathrm{~Hz}$ and the accelerometers at $100 \mathrm{~Hz}$. Following each session, the data were downloaded into the specialised analysis software (Viper, 2.1.3.0). Competitive match data were recorded using a semiautomated camera system (video (VID)) (TRACAB; ChyronHego, New York, USA) provided, as standard by the English Premier League. The raw data files were then imported into the GPS software and analysed in an identical manner.

The validity and reliability of both GPS and VID for quantifying the physical demands of team sports has been demonstrated by numerous studies. The interchangeability of the two systems has also been established. ${ }^{13}$ In addition, as part of internal club research, the two systems used in this study were tested during a number of discrete tasks within a footballspecific circuit, as well as during match play. Strong correlations $(\mathrm{r}=0.7-0.9, \mathrm{p}<0.05)$ and small percentage differences $(<10 \%)$ were found between GPS and VID for distances covered at all speeds except sprint distance, in line with previous work. ${ }^{13}$ Furthermore, both systems demonstrated good within player reliability (coefficient of variation $(\mathrm{CV})<5 \%$ ) and low percentage bias $(<10 \%)$ when compared with the criterion during the circuit.

For sessions when data were unavailable for a participant $(\mathrm{n}=1149$ of $10221 ; 11 \%)$ as a result of them not wearing a unit, not having match data, not completing the entire session or the data being deemed unreliable due to intermittent satellite signal, estimations were made as follows:

Main training session data: estimated by calculating squad averages for drills completed $(n=607$ of $10221 ; 6 \%)$.

International data: estimated by calculating the squad average of the other international players during the period of the international breaks ${ }^{14}$ ( $\mathrm{n}=306$ of $\left.10211 ; 3 \%\right)$.

Game data: matches were only monitored using VID from 2015/2016 onwards. Prior to this, match data were estimated using individual season game averages (from a minimum of three matches) from the data collected in 2015/2016 and 2016/2017. For players where this was not available $(n=6)$, estimations were made based on friendly matches in which GPS was worn. Game averages were extrapolated according to individual game time, as per previous work ${ }^{12}$ ( $n=236$ of $\left.10221 ; 2 \%\right)$.

The variables defined in table 1 were selected for use in this study due to their relevance to running loads (and potential injury). All variables were taken from the StatSports software (Viper).

\section{Definition of injury}

Injury information was classified by the club doctor and senior chartered physiotherapists. A recordable injury was defined as one that caused any absence from future football participation, that is, a time loss injury. ${ }^{15}$ Injuries were classified as being either: minimal (1-3 days of football activity missed), mild (4-7 days of football activity missed), moderate (1-4 weeks of football activity missed) or severe $(4+$ weeks of football activity missed). ${ }^{15}$ Injuries were also categorised by injury type and body site. The mechanism in which a participant acquired an injury was also classified as being non-contact or contact in nature.

\begin{tabular}{ll}
\hline Table 1 & Definition of workload variables \\
\hline Variable & Definition \\
\hline Total distance & Total covered $(\mathrm{m})$ : this includes walking, jogging, fast running and sprinting. \\
\hline Low-intensity distance & Total distance covered $(\mathrm{m})$ below $14.4 \mathrm{~km} / \mathrm{hour}$. \\
\hline High-speed running distance & Total distance covered $(\mathrm{m})$ between $19.8 \mathrm{~km} / \mathrm{hour}$ and $25.2 \mathrm{~km} / \mathrm{hour}$. \\
\hline Sprint distance & Total distance covered $(\mathrm{m})$ over $25.2 \mathrm{~km} / \mathrm{hour}$. \\
\hline Accelerations & An increase in GPS speed data for at least half a second with maximum acceleration in the period at least $0.5 \mathrm{~m} / \mathrm{s} / \mathrm{s}$. \\
\hline Decelerations & A decrease in GPS speed data for at least half a second with maximum deceleration in the period at least $0.5 \mathrm{~m} / \mathrm{s} / \mathrm{s}$. \\
\hline GPS, global positioning system. &
\end{tabular}


Table 2 Workload classifications and boundaries for accumulated workloads over 1-4 weeks

\begin{tabular}{|c|c|c|c|c|c|c|}
\hline & \multirow[b]{2}{*}{ Classification } & \multirow[b]{2}{*}{ Z-score } & \multicolumn{4}{|c|}{ No. of weeks accumulated } \\
\hline & & & 1 & 2 & 3 & 4 \\
\hline \multirow[t]{6}{*}{$\mathrm{TD}(\mathrm{m})$} & Very low & $\leq-2.00$ & 11150 & 24858 & 37202 & 45843 \\
\hline & Low & -1.99 to -1.00 & $11151-17539$ & $24859-35785$ & $37203-52504$ & $45844-67519$ \\
\hline & Low to moderate & -0.99 to 0.00 & $17540-24041$ & $35786-46733$ & $52505-68677$ & $67520-89707$ \\
\hline & Moderate to high & 0.00 to 0.99 & $24042-30549$ & $46734-57697$ & $68678-84830$ & $89708-111863$ \\
\hline & High & 1.00 to 1.99 & $30550-37065$ & $57698-68685$ & 84831-101176 & $111864-134050$ \\
\hline & Very high & $\geq 2.00$ & 37066 & 68686 & 101177 & 134051 \\
\hline \multirow[t]{6}{*}{ LID (m) } & Very low & $\leq-2.00$ & 9179 & 20347 & 30002 & 37324 \\
\hline & Low & -1.99 to -1.00 & $9180-14627$ & $20348-29653$ & $30003-43487$ & $37325-56070$ \\
\hline & Low to moderate & -0.99 to 0.00 & 14628-20108 & $29654-39026$ & $43488-57279$ & $56071-74824$ \\
\hline & Moderate to high & 0.00 to 0.99 & $20109-25644$ & $39027-48423$ & $57280-71110$ & $74825-93845$ \\
\hline & High & 1.00 to 1.99 & $25645-31160$ & $48424-57886$ & $71111-85119$ & $93846-112896$ \\
\hline & Very high & $\geq 2.00$ & 31161 & 57887 & 85120 & 112897 \\
\hline \multirow[t]{6}{*}{ HSD (m) } & Very low & $\leq-2.00$ & 110 & 509 & 904 & 1251 \\
\hline & Low & -1.99 to -1.00 & $111-542$ & $510-1215$ & $905-1861$ & $1252-2464$ \\
\hline & Low to moderate & -0.99 to 0.00 & 543-979 & 1216-1916 & $1862-2827$ & $2464-3702$ \\
\hline & Moderate to high & 0.00 to 0.99 & $980-1418$ & $1917-2624$ & 2828-3791 & $3703-4941$ \\
\hline & High & 1.00 to 1.99 & 1419-1853 & $2625-3326$ & $3792-4778$ & $4942-6176$ \\
\hline & Very high & $\geq 2.00$ & 1854 & 3327 & 4779 & 6177 \\
\hline \multirow[t]{6}{*}{$\mathrm{SD}(\mathrm{m})$} & Very low & $\leq-2.00$ & & & & \\
\hline & Low & -1.99 to -1.00 & $0-52$ & $0-149$ & $0-245$ & $0-336$ \\
\hline & Low to moderate & -0.99 to 0.00 & $53-210$ & $150-409$ & $246-600$ & $337-782$ \\
\hline & Moderate to high & 0.00 to 0.99 & $211-368$ & $410-672$ & $601-955$ & $783-1230$ \\
\hline & High & 1.00 to 1.99 & $369-528$ & $673-932$ & $956-1310$ & $1231-1680$ \\
\hline & Very high & $\geq 2.00$ & 529 & 933 & 1311 & 1681 \\
\hline \multirow[t]{6}{*}{ Acc (no.) } & Very low & $\leq-2.00$ & 862 & 1945 & 2832 & 3510 \\
\hline & Low & -1.99 to -1.00 & 863-1397 & $1946-2851$ & $2833-4166$ & $3511-5352$ \\
\hline & Low to moderate & -0.99 to 0.00 & 1398-1936 & $2852-3753$ & $4166-5510$ & $5353-7193$ \\
\hline & Moderate to high & 0.00 to 0.99 & $1937-2472$ & $3754-4662$ & $5511-6855$ & 7194-9042 \\
\hline & High & 1.00 to 1.99 & $2473-3010$ & $4663-5576$ & $6856-8200$ & $9043-10902$ \\
\hline & Very high & $\geq 2.00$ & 3011 & 5577 & 8201 & 10903 \\
\hline \multirow[t]{6}{*}{ Dec (no.) } & Very low & $\leq-2.00$ & 794 & 1795 & 2625 & 3242 \\
\hline & Low & -1.99 to -1.00 & $795-1287$ & $1796-2625$ & $2626-3842$ & $3243-4933$ \\
\hline & Low to moderate & -0.99 to 0.00 & 1288-1782 & $2626-3457$ & $3843-5073$ & $4934-6625$ \\
\hline & Moderate to high & 0.00 to 0.99 & $1783-2277$ & $3458-4292$ & $5074-6308$ & 6626-8323 \\
\hline & High & 1.00 to 1.99 & $2278-2771$ & $4293-5131$ & $6309-7459$ & 8324-10015 \\
\hline & Very high & $\geq 2.00$ & 2772 & 5132 & 7460 & 10016 \\
\hline
\end{tabular}

Acc, number of accelerations; Dec, number of decelerations; HSD, high-speed distance in metres; LID, low-intensity distance in metres; SD, sprint distance in metres; TD, total distance in metres.

\section{Data analyses}

Data were categorised in weekly blocks from Monday to Sunday. Every time a player participated in a training session or match, data were analysed in two ways. First, the previous 1-weekly, 2-weekly, 3 -weekly and 4-weekly loads were calculated. The loads were then classified into discrete ranges from very low through to very high using z-scores ${ }^{16}$ (table 2). The relationships between these weekly cumulative loads and subsequent injury were investigated. Injuries that occurred within the next 7 days were included for analysis. ${ }^{17}$

Second, the acute workload for the current week was calculated as the 1-week load and chronic workload as the previous 4-week rolling average acute workload. The acute and chronic workloads were uncoupled to prevent them being falsely correlated. The ACWR was calculated by dividing the acute workload by the chronic workload. ${ }^{18}$ Only acute workloads that were preceded by four complete weeks were included in the ratio calculations. A value of greater than 1 represents an acute workload greater than the chronic workload. Chronic workloads were also separated into high and low categories by the median score for each variable. ${ }^{19}$ From this, workload-injury relationships between ACWR ratios combined with high and low chronic workloads were analysed. As with accumulated workloads, the ratios were categorised based on z-scores (table 3). Only conditions that contained 20 or more injuries were included in the statistical analysis to allow for moderate to strong associations to be made. ${ }^{20}$ Consequently, data were excluded for incidences when the chronic workloads were high for both noncontact and contact injuries. This was also the case for contact injuries when the chronic loads were low.

\section{Statistical analyses}

The analysis was performed in a similar manner to the previous work of Hulin et al. ${ }^{18}$ Injury incidence was determined by dividing total number of injuries by the 'on-legs' exposure time and reported as rates per 1000 hours. Injury risks were calculated as the number of injuries sustained relative to the number of exposures to each 


\section{Original research}

Table 3 Workload classifications and boundaries for: (A) acute:chronic workload ratios overall, (B) acute:chronic workload ratios combined with high chronic workloads and (C) acute:chronic workload ratios combined with low chronic workloads

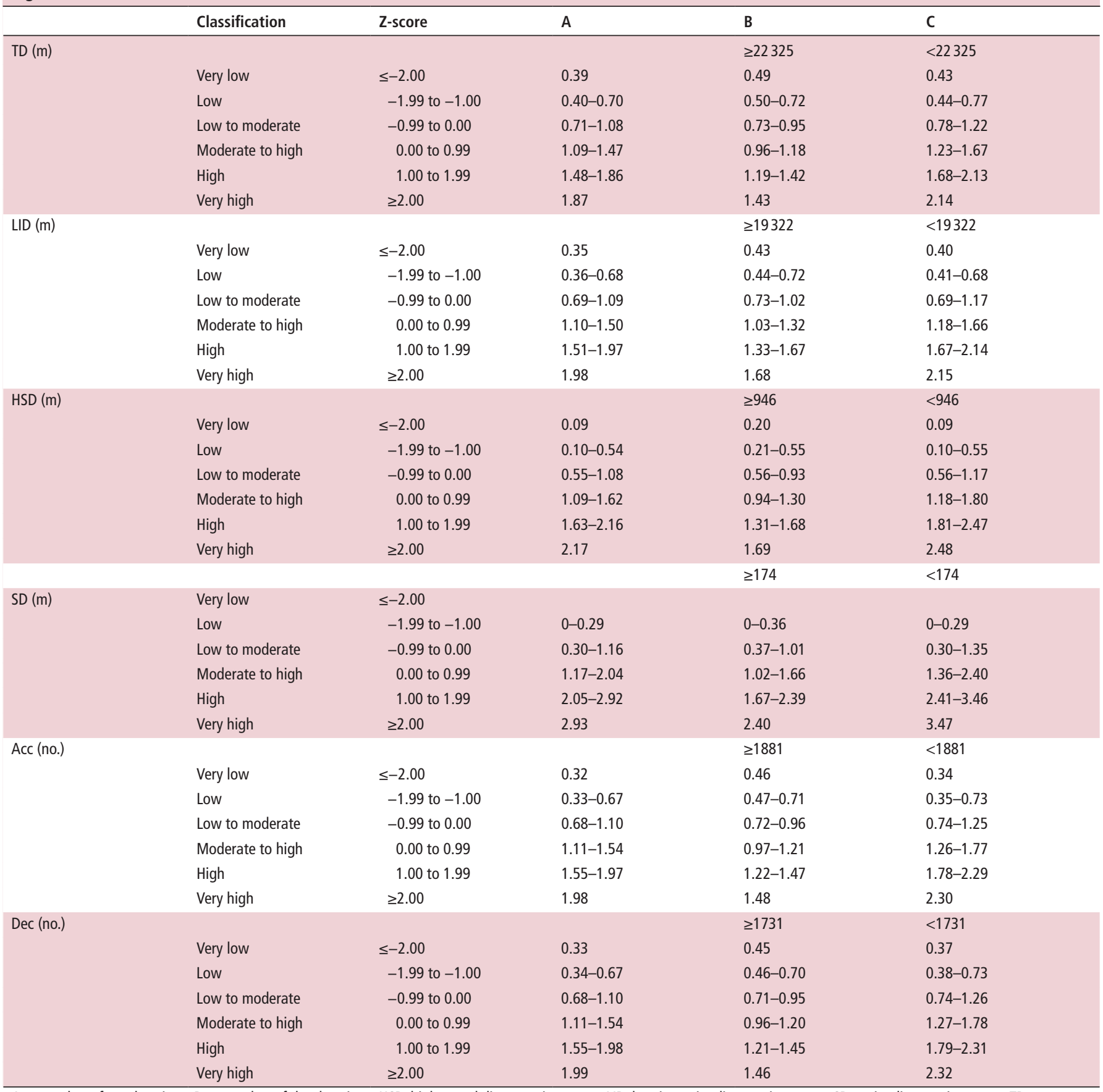

Acc, number of accelerations; Dec, number of decelerations; HSD, high-speed distances in metres; LID, low-intensity distance in metres; SD, sprint distance in metres; TD, total distance in metres.

workload classification. ${ }^{18}$ Exposure data were recorded as per the procedures outlined by the Fédération de Football Association Medical Assessment Research Centre. ${ }^{15}$ A binary logistic regression model was used to compare workloads between injured and non-injured players for all workload variables independently. Accumulated workload and ACWR were independently modelled as predictor variables. RR was then calculated using to determine the magnitude of the injury risk above and below given workloads or ratios (MedCalc Software, Ostend, Belgium). When an RR was greater than 1.00, an increased risk of injury was reported (ie, $\mathrm{RR}=1.50$ is indicative of a $50 \%$ increased risk) and vice versa. For an RR to be significant, 95\% CIs did not contain the null RR of 1.00 .
Data were analysed using IBM SPSS Statistics V.25.0 and reported as means and 95\%CI. Significance was accepted at $\mathrm{p}<0.05$.

\section{RESULTS}

\section{Injury incidence}

For the duration of the study, 132 injuries (13.3/1000 hours 'on-legs' exposure time) were recorded (2014-2015 season, 17.6/1000 hours; 2015-2016 season, 10.2/1000 hours; $2016-$ 2017 season, 12.4/1000 hours), including contact and noncontact injuries (see online supplementary appendix A). The knee was the most common site of injury across the three 
seasons (2.9/1000 hours), 69\% of which were non-contact injuries (2.0/1000 hours), predominantly meniscal or cartilage lesions and ligament sprains $(0.9$ and $0.7 / 1000$ hours, respectively). The ankle was the most common site of contact injury (1.9/1000 hours), with the most common type being ligament sprains (1.6/1000hours). The injury incidence in competition was over five times that of training $(33.7 / 1000$ hours vs $5.8 / 1000$ hours). In particular, contact injuries were considerably greater in competition than in training $(16.9 / 1000$ hours vs $1.3 / 1000$ hours). Despite a lower exposure to competition, $80 \%$ of contact injuries occurred in matches. The total number of days missed through injury was $4820(36.5 \pm 62.7$ [mean \pm SD] days per injury).

\section{Overall injuries}

A low chronic workload of ACC $(<1881)$, decelerations (DEC; <1731) and low-intensity distance (LID; <19222 m) combined with a very high ACWR (>2.0) elicited the greatest overall injury risk $(\mathrm{RR}=3.2,95 \% \mathrm{CI} 1.3$ to $7.6, \mathrm{p}=0.01$; $\mathrm{RR}=3.5,95 \%$ CI 1.5 to $8.2, \mathrm{p}=0.01$; and $\mathrm{RR}=2.76,95 \%$ CI 1.2 to6.6, $\mathrm{p}=0.02$, respectively). The risk was also significant for very high ACWR of the same metrics, plus total distance (TD), combined with all chronic loads $(\mathrm{RR}=2.4-2.6)$ (table 5). Conversely, a low ACWR of TD (0.4-0.7) for all chronic loads was associated with a decreased injury risk $(\mathrm{RR}=0.2,95 \% \mathrm{CI}$ 0.1 to $0.8, \mathrm{p}=0.02$ ).

\section{Non-contact injuries}

Low chronic workloads combined with very high ACWRs for TD $(>2.14)$, LID (>2.15), ACC (>2.30) and DEC (>2.32) resulted in a non-contact injury risk 5-7 times greater than ACWRs below this $(\mathrm{RR}=4.5$ (TD), $-6.6(\mathrm{DEC}), \mathrm{p}<0.05)$. Additionally, a low amount of TD accumulated over 4 weeks (45 844-67 $519 \mathrm{~m})$ also resulted in an increased risk $(\mathrm{RR}=2.2,95 \% \mathrm{CI} 1.0$ to $4.6, p=0.04$ ) (table 4). Significant risks were also found for TD, ACC, DEC and LID for all chronic loads when the ACWR was very high $(\mathrm{RR}=3.7-3.9)$ (table 5).

\section{Contact injuries}

Moderate to high ACWR (1.1-1.5) for TD, DEC and LID produced the largest contact injury risk $(\mathrm{RR}=2.0,95 \% \mathrm{CI} 1.0$ to $4.0, \mathrm{p}=0.04 ; \mathrm{RR}=2.0,95 \% \mathrm{CI} 1.0$ to $4.0, \mathrm{p}=0.04$; and $\mathrm{RR}=2.6$, $95 \%$ CI 1.3 to $5.2, \mathrm{p}=0.01$, respectively). A moderate to high amount of TD (24042-30549 m) and a low to moderate amount of DEC (1288-1782) accumulated over a week also showed a heightened risk of contact injury ( $R R=2.1,95 \%$ CI 1.1 to 4.0 , $\mathrm{p}=0.03$ and $\mathrm{RR}=2.0,95 \%$ CI 1.1 to $3.9, \mathrm{p}=0.03$, respectively).

\section{DISCUSSION}

This is the first study to explore the relationship of both accumulated GPS-derived loads and ACWR with contact and noncontact injury risk at an English Premier League football club. This extends our previous work, ${ }^{5}$ and that of others, ${ }^{7} 18192122$ showing that a number of GPS-derived workloads were associated with injury risk.

\section{Non-contact injuries and workload}

A very high ACWR combined with low chronic workload categories demonstrated the greatest non-contact injury risk for most metrics (except high-speed distance [HSD] and sprint distance [SD]), with DEC being most strongly associated with RR (ACWR $>2.3, \mathrm{RR}=6.6$ ). When all chronic workloads were analysed, a very high ACWR demonstrated a lesser but still significant risk for the same metrics $(\mathrm{RR}=3.7-3.9)$. These findings are in line with studies in cricket, ${ }^{18}$ rugby, ${ }^{19}{ }^{22}$ Australian football, ${ }^{23}$ Gaelic football ${ }^{24}$ and football ${ }^{5}$ where high ACWR, referred to as 'spikes' in workload, have been associated with heightened injury risk. Due to the inevitable increased exposure to risk with greater workloads, previous research has focused on the higher loadhigher injury risk relationship. ${ }^{725}$ However, the above findings, alongside the lack of significant risks associated with high accumulated loads in this study, support a growing body of literature suggesting that acute, excessive, rapid increases in loads may be responsible for a large proportion of non-contact injuries, rather than chronic exposure to higher loads. ${ }^{10}$

The protective effect of high chronic loads versus low chronic loads has been reported in rugby. ${ }^{19} 22$ They concluded that the players who were capable of achieving high exposure had the enhanced physical attributes needed for decreased injury risk. This theory has recently been demonstrated in hurling, where players with well-developed lower body strength, repeated sprint ability and speed tolerated higher training loads and had a reduced risk of injury compared with lower performance groups. ${ }^{26}$ In youth football, a high ACWR combined with low chronic HSD load showed a significantly increased risk of noncontact injury $(\mathrm{ACWR}=1.4-2.0, \mathrm{RR}=2.6)$, which was not evident when combined with high chronic HSD (ACWR $=1.3-$ $1.8, \mathrm{RR}=0.5) .^{5}$

In the current study, there were not enough injuries when the chronic workloads were high to determine the RRs of noncontact injury, further indicating a potential protective effect. Ultimately, training at higher workloads may cause players to develop a greater tolerance for the increasing intensity and fatigue of competition. ${ }^{10}$ Concurrently, reducing training loads, while lowering a player's exposure to risk, may also have a negative effect on fitness and physical preparedness, potentially increasing the risk. Therefore, as per the training-injury prevention paradox model, ${ }^{10}$ optimal load management to minimise injury risk should involve appropriate, progressive exposure to higher loads while avoiding training load spikes that the player is not prepared for.

\section{Contact injuries and workload}

Very little research has investigated the relationship between contact injuries and workload, despite early workload-injury research suggesting that players with better developed physical capacity may be at less risk of contact injury. ${ }^{27}$ In the current study, $80 \%$ of all contact injuries occurred in matches, similar to previous injury incidence reports. ${ }^{28}$ This may be due to the high speed and intensity of play, resulting in more body contact such as sliding and tackling. ${ }^{29}$ The risk of contact injury was greatest when the ACWR was moderate to high for TD, LID and DEC $(\mathrm{RR}$ range $=2.0-2.6)$, meaning the acute workload was very similar to the chronic workload.

Also, as load was categorised by z-scores, contact risk was highest for the most commonly occurring ratios $(z=0.0-1.0)$. Players who are regularly in the team, and therefore more at risk of contact injury, typically have a lack of variation in their workload due to a large proportion of the weekly load being attained from matches. Therefore, when the match load was constant, variations in the training load produced very little fluctuation in the total acute load. ${ }^{23}$ Thus, it would appear that in the current study, contact injury is most likely to be related to match exposure, rather than the prescribed workload. The lack of association of the ACWR to contact injuries is highlighted 


\section{Original research}

Table 4 Injury risk associated with accumulated workloads over 1-4 weeks

\begin{tabular}{|c|c|c|c|c|c|c|c|c|c|c|c|c|c|}
\hline \multirow{2}{*}{$\begin{array}{l}\text { No. of weeks } \\
\text { accumulated }\end{array}$} & & \multicolumn{3}{|l|}{1} & \multicolumn{3}{|l|}{2} & \multicolumn{3}{|l|}{3} & \multicolumn{3}{|l|}{4} \\
\hline & & NC & $\mathrm{C}$ & Overall & NC & C & Overall & NC & C & Overall & NC & $\mathrm{C}$ & Overall \\
\hline \multirow[t]{6}{*}{ TD (m) } & Very low & 0.49 & 0.67 & 0.28 & 1.38 & 0.94 & 1.19 & 1.55 & 2.17 & 1.81 & 0.92 & 1.28 & 1.07 \\
\hline & Low & 0.94 & 0.16 & 0.59 & 1.11 & 1.01 & 1.07 & 1.26 & 0.32 & 0.84 & $2.18^{*}$ & 0.66 & 1.49 \\
\hline & $\begin{array}{l}\text { Low to } \\
\text { moderate }\end{array}$ & 1.51 & 0.85 & 1.20 & 1.03 & 0.86 & 0.95 & 1.00 & 0.69 & 0.86 & 0.97 & 0.63 & 0.82 \\
\hline & $\begin{array}{l}\text { Moderate to } \\
\text { high }\end{array}$ & 0.80 & $2.09 *$ & 1.22 & 1.10 & 1.73 & 1.33 & 0.96 & 1.55 & 1.18 & 0.81 & 1.79 & 1.13 \\
\hline & High & 0.84 & 0.93 & 0.88 & 0.57 & 0.18 & $0.40^{*}$ & 0.66 & 0.68 & 0.67 & 0.92 & 0.48 & 0.73 \\
\hline & Very high & 1.01 & 1.39 & 1.17 & 1.29 & 1.78 & 1.50 & 1.52 & 2.11 & 1.77 & 0.86 & 2.57 & 1.07 \\
\hline \multirow[t]{6}{*}{ LID (m) } & Very low & 0.40 & 0.55 & 0.23 & 1.32 & 0.89 & 1.14 & 0.51 & 2.23 & 1.20 & 0.91 & 1.26 & 1.06 \\
\hline & Low & 0.81 & 0.34 & 0.60 & 1.15 & 1.34 & 1.23 & 1.55 & 0.32 & 1.00 & 1.27 & 0.66 & 1.00 \\
\hline & $\begin{array}{l}\text { Low to } \\
\text { moderate }\end{array}$ & 1.17 & 1.11 & 1.15 & 0.98 & 1.19 & 1.06 & 1.06 & 0.88 & 0.98 & 1.36 & 0.95 & 1.18 \\
\hline & $\begin{array}{l}\text { Moderate to } \\
\text { high }\end{array}$ & 1.14 & 1.65 & 1.34 & 1.15 & 1.13 & 1.14 & 0.77 & 1.30 & 0.97 & 0.70 & 1.32 & 0.93 \\
\hline & High & 0.84 & 0.93 & 0.88 & 0.58 & 0.38 & 0.49 & 1.02 & 0.92 & 0.98 & 1.07 & 0.70 & 0.91 \\
\hline & Very high & 1.01 & 0.65 & 0.58 & 1.18 & 0.76 & 0.68 & 2.63 & 0.83 & 1.50 & 0.86 & 1.18 & 0.50 \\
\hline \multirow[t]{6}{*}{ HSD (m) } & Very low & 2.61 & 3.57 & 1.52 & 3.23 & 1.01 & 1.83 & 0.44 & 0.60 & 0.25 & 1.43 & 0.97 & 1.23 \\
\hline & Low & 1.15 & 0.17 & 0.70 & 1.46 & 0.59 & 1.07 & 1.52 & 0.85 & 1.22 & 1.49 & 0.70 & 1.14 \\
\hline & $\begin{array}{l}\text { Low to } \\
\text { moderate }\end{array}$ & 0.86 & 1.07 & 0.94 & 0.92 & 1.58 & 1.16 & 0.99 & 1.36 & 1.34 & 0.87 & 1.00 & 0.92 \\
\hline & $\begin{array}{l}\text { Moderate to } \\
\text { high }\end{array}$ & 1.16 & 1.33 & 1.23 & 0.89 & 0.99 & 0.93 & 0.74 & 0.79 & 0.76 & 0.98 & 0.82 & 0.91 \\
\hline & High & 1.33 & 1.61 & 1.44 & 0.76 & 0.40 & 0.60 & 1.59 & 0.89 & 1.28 & 0.65 & 1.46 & 1.19 \\
\hline & Very high & 0.24 & 0.68 & 0.28 & 0.78 & 2.22 & 1.37 & 0.36 & 2.18 & 0.89 & 0.49 & 2.45 & 1.00 \\
\hline \multirow[t]{6}{*}{$\mathrm{SD}(\mathrm{m})$} & Very low & & & & & & & & & & & & \\
\hline & Low & 1.10 & 0.13 & 0.60 & 1.20 & 0.78 & 1.02 & 1.29 & 0.44 & 0.88 & 1.83 & 0.65 & 1.29 \\
\hline & $\begin{array}{l}\text { Low to } \\
\text { moderate }\end{array}$ & 1.16 & 1.31 & 1.22 & 1.16 & 0.90 & 1.04 & 1.00 & 1.19 & 1.04 & 1.06 & 1.22 & 1.13 \\
\hline & $\begin{array}{l}\text { Moderate to } \\
\text { high }\end{array}$ & 1.08 & 1.16 & 1.12 & 1.01 & 1.24 & 1.10 & 1.23 & 0.72 & 0.98 & 0.98 & 0.59 & 0.62 \\
\hline & High & 0.82 & 0.85 & 0.83 & 0.41 & 0.87 & 0.60 & 0.36 & 1.76 & 1.16 & 0.65 & 1.39 & 1.14 \\
\hline & Very high & 0.23 & 1.36 & 0.55 & 0.96 & 1.34 & 1.12 & 0.97 & 1.32 & 0.82 & 0.49 & 2.15 & 1.16 \\
\hline \multirow[t]{6}{*}{ Acc (no.) } & Very low & 0.45 & 0.61 & 0.26 & 1.18 & 0.80 & 1.02 & 0.48 & 2.10 & 1.13 & 1.28 & 1.16 & 1.23 \\
\hline & Low & 0.93 & 0.33 & 0.67 & 1.18 & 1.06 & 1.13 & 1.50 & 0.64 & 1.12 & 1.06 & 0.71 & 0.91 \\
\hline & $\begin{array}{l}\text { Low to } \\
\text { moderate }\end{array}$ & 1.08 & 1.62 & 1.29 & 1.31 & 1.89 & $1.53^{*}$ & 1.10 & 0.92 & 1.02 & 0.99 & 1.00 & 0.99 \\
\hline & $\begin{array}{l}\text { Moderate to } \\
\text { high }\end{array}$ & 1.28 & 0.74 & 1.03 & 0.85 & 0.68 & 0.78 & 0.81 & 1.10 & 0.92 & 1.04 & 1.41 & 1.18 \\
\hline & High & 0.70 & 1.45 & 0.99 & 0.56 & 0.37 & 0.48 & 1.02 & 0.67 & 0.87 & 0.85 & 0.22 & 0.57 \\
\hline & Very high & 1.12 & 1.54 & 1.30 & 1.71 & 2.36 & 1.98 & 2.14 & 2.96 & 2.48 & 1.39 & 4.24 & 1.76 \\
\hline \multirow[t]{6}{*}{ Dec (no.) } & Very low & 0.50 & 0.69 & 0.29 & 1.32 & 0.89 & 1.14 & 0.48 & 0.72 & 1.15 & 1.39 & 1.17 & 0.98 \\
\hline & Low & 1.04 & 0.32 & 0.71 & 0.91 & 1.61 & 1.19 & 1.40 & 0.60 & 1.05 & 1.09 & 0.73 & 0.94 \\
\hline & $\begin{array}{l}\text { Low to } \\
\text { moderate }\end{array}$ & 0.89 & $2.04^{*}$ & 1.29 & 1.11 & 1.34 & 1.20 & 1.21 & 0.92 & 1.08 & 1.03 & 1.08 & 1.05 \\
\hline & $\begin{array}{l}\text { Moderate to } \\
\text { high }\end{array}$ & 1.31 & 0.55 & 0.94 & 1.13 & 0.79 & 0.97 & 0.69 & 1.14 & 0.86 & 1.08 & 1.31 & 1.17 \\
\hline & High & 0.84 & 1.46 & 1.09 & 0.55 & 0.37 & 0.47 & 1.18 & 0.65 & 0.95 & 0.84 & 0.22 & 0.56 \\
\hline & Very high & 1.06 & 1.47 & 1.23 & 1.64 & 2.27 & 1.91 & 2.04 & 2.82 & 2.37 & 1.30 & 3.96 & 1.64 \\
\hline
\end{tabular}

Acc, number of accelerations; Dec, number of decelerations; HSD, high-speed distances in metres; LID, low-intensity distance in metres (m); SD, sprint distance in metres; TD, total distance in metres, $\mathrm{N}$, non-contact injury; $\mathrm{C}$, contact injury, ${ }^{*}, \mathrm{p}<0.05 ;{ }^{*}{ }^{*}, \mathrm{p}<0.01$.

further by the large RR of non-contact injury following an acute spike compared with overall injury, suggesting that including contact injuries reduces the association of the ACWR with injury risk. Consequently, these injuries should be analysed separately when establishing workloadinjury relationships and determining uniform injury definitions across research. ${ }^{30}$
Potential limitations

Previous studies have highlighted the limitations of using estimated match data, as it does not account for match to match variability. ${ }^{14}$ This study has attempted to improve on this by including match data for the 2015/2016 and 2016/2017 seasons. However, for the 2014/2015 season, TRACAB data were not available, resulting in estimations being calculated as 
Table 5 Injury risks associated with (A) acute:chronic workload ratios overall, (B) acute:chronic workload ratios combined with high chronic workloads and (C) acute:chronic workload ratios combined with low chronic workloads

\begin{tabular}{|c|c|c|c|c|c|c|c|c|c|c|c|c|c|}
\hline & & \multicolumn{4}{|l|}{ A } & \multicolumn{4}{|l|}{ B } & \multicolumn{4}{|l|}{ C } \\
\hline & & NC & $\mathrm{C}$ & & Overall & NC & C & & Overall & NC & C & & Overall \\
\hline \multirow[t]{5}{*}{$\mathrm{TD}(\mathrm{m})$} & Very low & & & & & & & & 2.04 & & & & \\
\hline & High & 0.84 & 1.46 & 1.09 & 0.55 & 0.37 & 0.47 & 1.18 & 0.65 & 0.95 & 0.84 & 0.22 & 0.56 \\
\hline & Very high & 1.06 & 1.47 & 1.23 & 1.64 & 2.27 & 1.91 & 2.04 & 2.82 & 2.37 & 1.30 & 3.96 & 1.64 \\
\hline & Low to moderate & 1.32 & 0.69 & 1.01 & & & & 1.01 & & 1.56 & & 1.22 & \\
\hline & Very high & $3.67^{*}$ & 0.88 & $2.40^{*}$ & & & & 0.80 & & $4.50^{*}$ & & 2.61 & \\
\hline \multirow[t]{4}{*}{ LID (m) } & Very low & & & & & & & 2.79 & & & & & \\
\hline & Low & 0.39 & 0.25 & 0.33 & & & & 0.30 & & 0.25 & & 0.16 & \\
\hline & Low to moderate & 0.83 & 0.48 & 0.66 & & & & 0.80 & & 1.15 & & 1.00 & \\
\hline & Moderate to high & 1.52 & $2.60^{*}$ & 1.91 * & & & & $2.08^{*}$ & & 0.85 & & 1.13 & \\
\hline \multirow{5}{*}{$\mathrm{HSD}(\mathrm{m})$} & Low & 1.35 & 0.26 & 0.85 & & & & 0.80 & & 1.67 & & 0.97 & \\
\hline & Low to moderate & 0.92 & 1.64 & 1.18 & & & & 0.84 & & 1.73 & & 1.78 & \\
\hline & Moderate to high & 1.20 & 0.80 & 1.02 & & & & 1.36 & & 0.70 & & 0.72 & \\
\hline & High & 0.52 & 1.07 & 0.75 & & & & 1.36 & & 0.39 & & 0.48 & \\
\hline & Very high & 0.66 & 0.88 & 0.76 & & & & 0.38 & & 0.39 & & 0.51 & \\
\hline \multirow[t]{6}{*}{$\mathrm{SD}(\mathrm{m})$} & Very low & & & & & & & & & & & & \\
\hline & Low & 1.05 & 0.15 & 0.57 & & & & 0.24 & & 1.25 & & 0.75 & \\
\hline & Low to moderate & 0.72 & 1.40 & 0.96 & & & & 1.68 & & 0.66 & & 0.83 & \\
\hline & Moderate to high & 1.10 & 1.12 & 1.11 & & & & 0.65 & & 1.31 & & 1.40 & \\
\hline & High & 1.36 & 0.86 & 1.14 & & & & 1.78 & & 1.34 & & 1.10 & \\
\hline & Very high & 1.96 & 0.82 & 1.46 & & & & 0.58 & & 1.01 & & 0.63 & \\
\hline \multirow{5}{*}{ Dec (no.) } & Low & 0.44 & 0.28 & 0.37 & & & & 0.18 & & 0.16 & & 0.09 & \\
\hline & Low to moderate & 0.88 & 0.80 & 0.85 & & & & 0.98 & & 1.41 & & 1.40 & \\
\hline & Moderate to high & 1.23 & $1.99^{*}$ & 1.52 & & & & 1.31 & & 0.71 & & 0.86 & \\
\hline & High & 0.34 & 0.45 & 0.39 & & & & 1.29 & & 0.25 & & 0.64 & \\
\hline & Very high & $3.73^{*}$ & 0.89 & $2.44^{*}$ & & & & 0.88 & & $6.58^{* *}$ & & $3.47^{*}$ & \\
\hline
\end{tabular}

Acc, number of accelerations; $C$, contact injury; Dec, number of decelerations; HSD, high-speed distances in metres; LID, low-intensity distance in metres; N, non-contact injury; $\mathrm{SD}$, sprint distance in metres; TD, total distance in metres; ${ }^{*}, \mathrm{p}<0.05 ;{ }^{* *}, \mathrm{p}<0.01$.

per previous work, ${ }^{12}$ emulating the aforementioned limitation. Additionally, as the match data for the latter two seasons were collected using a different system than training, the precision and sensitivity of the data may be decreased, despite it being calibrated to maximise between system agreements. ${ }^{13}$ With technological advancements, and the recent admittance of GPS in league matches, future research should aim to use a single monitoring system for both competition and training.

One potential explanation for the lack of significant noncontact injury risk for very high acute HSD and SD, despite all other metrics reporting otherwise, may be the use of absolute speed thresholds in this study. Buchheit ${ }^{14}$ recently stated that the use of fixed thresholds may reduce the sensitivity of the ACWR due to the varying locomotor profiles between players, particularly as subtle differences in speed at high intensity have been found to have important implications on injury risk. Future research could consider the use of individualised thresholds, although caution must be taken when anchoring all locomotor categories to one fitness measure. ${ }^{31}$

The present study only examined external load; however, the incorporation of the rating of perceived exertion (RPE) values, as a measure of internal workload, may provide a more complete insight into the likelihood of injury, as well as taking into consideration the athlete's response to a given workload. ${ }^{17}$ Fanchini et $a l^{21}$ recently analysed the ACWR in relation to injury risk in elite football using RPE as their load measure. Similar to the current study and the previous work of the authors, ${ }^{5}$ they demonstrated a heightened risk with acute 'spikes'. A combination of both methods may give a more complete assessment of load-related risk, while also considering 
the validity and specificity of the chosen metrics to the sport and the individual. ${ }^{32}$

Calculating the ACWR using rolling averages is evidence based and supported by a large body of literature. However, future research may consider using exponentially weighted moving averages, which consider the decaying nature of fitness and fatigue over time. This method has recently been shown to have a greater sensitivity to increases in injury risk at higher ACWRs. ${ }^{33}$

The statistical power of this study was not calculated prospectively. As retrospective power analysis calculations are not appropriate, ${ }^{34}$ the power analysis was not included. However, this study included 81 injury cases, which is enough to make moderate to strong associations regarding injury risk factors. ${ }^{20}$ Future studies should ensure prospective power analysis for inclusion. Furthermore, as commonly recommended in elite sport research, future work involving multiple clubs would enhance the ability to generalise these findings, advance the statistical analysis and detect small to moderate associations $(+200$ injury cases).

\section{SUMMARY AND CONCLUSIONS}

In summary, ACWR had a stronger association to non-contact injury risk in this cohort of English Premier League football players than accumulated loads, suggesting the rapid increase in load is more indicative of injury than the cumulative amount of load performed. Specifically, very high acute spikes when the chronic loads were low corresponded to the greatest non-contact injury risk. We recommend that training programmes should involve progressive exposure to higher loads to enhance physical capacities while minimising the risks associated with rapid, excessive spikes. Due to the majority of contact injuries occurring during competition, which is both inevitable and relatively non-modifiable by practitioners, it is unlikely that they were associated with a given workload. While this study provides an initial insight into the relationships between workload an injury risk, care should be taken when applying the findings beyond the studied population.

Data were excluded for categories were there were less than 20 injuries, as moderate to strong associations between workload and injury could not be made. ${ }^{20}$

\section{What are the findings?}

- For English Premier League football players, when chronic load exposure is low, an acute:chronic workload ratio (ACWR) $>2$ is associated with 5-7 times the risk of a soft tissue injury than players whose ACWR is below this.

- Regardless of chronic exposure, a spike in workload is associated with increased injury risk, although this risk is lessened with greater chronic loads.

- A spike in decelerations was associated with the greatest non-contact injury risk.

\section{How might it impact on clinical practice in the future?}

- Our data provide initial recommendations for monitoring ACWRs in English Premier League football players.

- We highlight some global positioning system-derived variables that may serve practitioners who monitor elite football players' workload to prevent injury.
Contributors All authors listed met the conditions required for full authorship. LB designed the initial study proposal, which was presented to ASG, SB-L and MG. From there, all five authors met regularly to ensure a scientifically sound study design was created. LB collated and analysed the data with the help of both ASG and MG throughout the process. F-XL and SB-L advised and checked the statistical analysis. LB wrote the main body of the article, which was revised multiple times by all authors before being approved for publication. LB modified the article following revisions with contributions from SB-L. All authors are fully aware and understanding of the findings of the study and confident in the integrity of the research.

Funding The authors have not declared a specific grant for this research from any funding agency in the public, commercial or not-for-profit sectors.

Competing interests None declared.

Patient consent for publication Not required.

Ethics approval Approval was obtained from the University of Birmingham Ethical Review Committee.

Provenance and peer review Not commissioned; externally peer reviewed.

Data sharing statement All data analysed are included in the article.

Open access This is an open access article distributed in accordance with the Creative Commons Attribution Non Commercial (CC BY-NC 4.0) license, which permits others to distribute, remix, adapt, build upon this work non-commercially, and license their derivative works on different terms, provided the original work is properly cited, appropriate credit is given, any changes made indicated, and the use is non-commercial. See: http://creativecommons.org/licenses/by-nc/4.0/.

\section{ORCID iD}

Laura Bowen http://orcid.org/0000-0001-8361-5219

\section{REFERENCES}

1 Ekstrand J, Hägglund M, Waldén M. Injury incidence and injury patterns in professional football: the UEFA injury study. Br J Sports Med 2011;45:553-8.

2 https://www.jltspecialty.com/media-centre/press-release/2017/june/injury-costs-forpremier-league-clubs (accessed 20 Mar 2018).

3 Hägglund $M$, Waldén $M$, Magnusson $H$, et al. Injuries affect team performance negatively in professional football: an 11-year follow-up of the UEFA Champions League injury study. Br J Sports Med 2013;47:738-42.

4 Windt J, Gabbett TJ. How do training and competition workloads relate to injury? The workload-injury aetiology model. Br J Sports Med 2017;51:428-35.

5 Bowen L, Gross AS, Gimpel M, et al. Accumulated workloads and the acute:chronic workload ratio relate to injury risk in elite youth football players. Br J Sports Med 2017:51:452-9.

6 Lu D, Howle K, Waterson A, et al. Workload profiles prior to injury in professional soccer players. Sci Med Football 2017:1:237-43.

7 Malone S, Owen A, Newton M, et al. The acute: chonic workload ratio in relation to injury risk in professional soccer. J Sci Med Sport 2017;20:561-5.

8 Barnes C, Archer DT, Hogg B, et al. The evolution of physical and technical performance parameters in the English Premier League. Int J Sports Med 2014:35:1095-100.

9 SELYE H. The general adaptation syndrome and the diseases of adaptation. J Clin Endocrinol Metab 1946:6:117-230.

10 Gabbett TJ. The training-injury prevention paradox: should athletes be training smarter and harder? Br J Sports Med 2016:50:273-80.

11 Banister E, Calvert T, Savage M, et al. A systems model of training for athletic performance. Aus J Sports Med 1975;7:57-61.

12 Ehrmann FE, Duncan CS, Sindhusake D, et al. GPS and injury prevention in professional soccer. J Strength Cond Res 2016:30:360-7.

13 Buchheit M, Allen A, Poon TK, et al. Integrating different tracking systems in football: multiple camera semi-automatic system, local position measurement and GPS technologies. J Sports Sci 2014;32:1844-57.

14 Buchheit M. Applying the acute:chronic workload ratio in elite football: worth the effort? Br J Sports Med 2017:51:1325-7.

15 Fuller $C$, Ekstrand J, Junge $A$, et al. Consensus statement on injury definitions and data collection procedures in studies of football (soccer) injuries. Br J Sports Med 2006;16:83-92.

16 Wang Y, Chen HJ. Use of percentiles and z-scores in anthropometry. In: Preedy VR, ed. Handbook of anthropometry: physical measures of human form in health and disease. New York, NY: Springer Science and Business Media, 2012:29-48.

17 Piggott B, Newton M, McGuigan M. The relationship between training load and incidence of injury and illness over a pre-season at an Australian football league club. J Aust Strength Cond Res 2008;17:4-17.

18 Hulin BT, Gabbett TJ, Blanch P, et al. Spikes in acute workload are associated with increased injury risk in elite cricket fast bowlers. Br J Sports Med 2014;48:708-12.

19 Hulin BT, Gabbett TJ, Lawson DW, et al. The acute:chronic workload ratio predicts injury: high chronic workload may decrease injury risk in elite rugby league players. $\mathrm{Br}$ J Sports Med 2016;50:231-6. 
20 Bahr R, Holme I. Risk factors for sports injuries—a methodological approach. Br J Sports Med 2003;37:384-92.

21 Fanchini M, Rampinini E, Riggio M, et al. Despite association, the acute:chronic work load ratio does not predict non-contact injury in elite footballers. Sci Med Football 2018;2:108-14.

22 Hulin BT, Gabbett TJ, Caputi P, et al. Low chronic workload and the acute:chronic workload ratio are more predictive of injury than between-match recovery time: a two-season prospective cohort study in elite rugby league players. Br I Sports Med 2016;50:1008-12.

23 Stares J, Dawson B, Peeling P, et al. Identifying high risk loading conditions for inseason injury in elite Australian football players. J Sci Med Sport 2018;21:46-51.

24 Malone S, Roe M, Doran DA, et al. Aerobic fitness and playing experience protect against spikes in workload: the role of the acute: chronic workload ratio on injury risk in elite Gaelic football. Int I Sports Physiol Perform 2016;24:1-25.

25 Gabbett TJ, Jenkins DG. Relationship between training load and injury in professional rugby league players. J Sci Med Sport 2011;14:204-9.

26 Malone S, Hughes B, Doran DA, et al. Can the workload-injury relationship be moderated by improved strength, speed and repeated-sprint qualities? I Sci Med Sport 2019:22:29-34.
27 Gabbett TJ. The development and application of an injury prediction model for noncontact, soft-tissue injuries in elite collision sport athletes. I Strength Cond Res 2010;24:2593-603.

28 Hawkins RD, Fuller CW. A prospective epidemiological study of injuries in four English professional football clubs. Br I Sports Med 1999;33:196-203.

29 Wong P, Hong Y. Soccer injury in the lower extremities. Br J Sports Med 2005;39:473-82.

30 Hulin BT. The never-ending search for the perfect acute:chronic workload ratio: what role injury definition? Br J Sports Med 2017;51:991-2.

31 Hunter F, Bray J, Towlson C, et al. Individualisation of time-motion analysis: a method comparison and case report series. Int I Sports Med 2015;36:41-8.

32 Blanch $\mathrm{P}$, Gabbett $\mathrm{TJ}$. Has the athlete trained enough to return to play safely? The acute:chronic workload ratio permits clinicians to quantify a player's risk of subsequent injury. Br J Sports Med 2016;50:471-5.

33 Murray NB, Gabbett TJ, Townshend AD, et al. Calculating acute:chronic workload ratios using exponentially weighted moving averages provides a more sensitive indicator of injury likelihood than rolling averages. Br J Sports Med 2017;51:749-54.

34 Zumbo BD, Hubley AM. A note on misconceptions concerning prospective and retrospective power. J R Stat Soc Ser D Stat 1998:47:385-8. 